\title{
ST-elevation acute coronary syndrome in a patient after heart transplant
}

\author{
Aldona Browarek, Artur Dębski, Paweł Tyczyński, Małgorzata Piotrowska, Tomasz Zieliński, \\ Małgorzata Sobieszczańska-Małek, Maciej Karcz, Adam Witkowski \\ Institute of Cardiology, Warsaw, Poland
}

Postep Kardiol Inter 2014; 10, 1 (35): 60-62

DOI: $10.5114 /$ pwki.2014.41474

\begin{abstract}
A b stract
The accelerated process of vasculopathy in heart transplant $(\mathrm{HTX})$ recipients is a well-known factor of increased morbidity and mortality among this subset of patients. Heart transplant patients with acute coronary syndrome (ACS) usually do not present with typical symptoms. ST elevation (STE) is a very rare presentation of ACS in HTx recipients. We report a case of a female HTx patient, in whom STE-ACS was diagnosed and was subsequently treated with primary percutaneous coronary intervention.
\end{abstract}

Key words: ST-elevation myocardial infarction, heart transplant, cardiac allograft vasculopathy.

\section{Case report}

The 55-year-old female patient underwent heart transplant (HTx) for heart failure secondary to hypertrophic cardiomyopathy 5 years ago. Immunosuppression consisted of tacrolimus, mycophenolate mofetil and corticosteroids up to 12 months after HTx.

The early post-transplantation course had been complicated by acute cellular rejection (ACR) grade 2R (according to ISHLT grading scale) treated with methylprednisolone boluses and with cytomegalovirus infection. The patient was also treated due to sinus node dysfunction with implantation of a dual-chamber pacemaker. The patient remained without classical risk factors for atherosclerosis (no-smoker, body mass index $23 \mathrm{~kg} / \mathrm{m}^{2}$, normal blood pressure and lipid profile).

Angiography done 1 year after HTx showed normal coronary arteries and 3 years after surgery only discrete lesions (Figure 1). Neither ACR nor antibody-mediated rejection were found in protocol myocardial biopsy done 3 years after $\mathrm{HTX}$.

The patient was admitted in the $5^{\text {th }}$ year after HTx to hospital due to unspecific weakness and left arm numbness for 4 days.

ECG revealed ST-segment elevation (STE) in V4-V6 leads along with $\mathrm{Q}$ wave. Maximal troponin- $\mathrm{T}$ rise was
$5.2 \mathrm{ng} / \mathrm{ml}$ (UNL $0.014 \mathrm{ng} / \mathrm{ml})$. ST elevation-acute coronary syndrome (STE-ACS) was diagnosed.

Emergent angiography revealed left anterior descending coronary artery (LAD) occlusion in its proximal segment and $70-80 \%$ stenosis in the proximal right coronary artery (RCA) (Figure 2). A loading dose of prasugrel was administered and immediate percutaneous coronary intervention $(\mathrm{PCI})$ of the $\mathrm{LAD}$ was performed. After opening the occluded LAD segment and predilatation, a $2.5 \mathrm{~mm} \times 28 \mathrm{~mm}$ everolimus-eluting stent was implanted at $14 \mathrm{~atm}$. A good angiographic result with TIMI 3 flow was achieved (Figure 3).

Echocardiography revealed akinesis of apical and mid segments of the anterior wall, septum and lateral wall with ejection fraction (EF) of $30 \%$ (as compared to normal left ventricular function 6 months ago) and mild improvement 1 month after ACS (EF 35-40\%).

Recovery was uncomplicated. One month later the patient underwent elective $\mathrm{PCl}$ of the RCA with implantation of a $2.75 \mathrm{~mm} \times 22 \mathrm{~mm}$ zotarolimus-eluting stent.

The patient remains under strict clinical vigilance for possible progression of vasculopathy.

\section{Discussion}

Acute coronary syndrome in HTx patients is uncommon [1], and reports of STE presentation of ACS are ca-

Corresponding author:

Pawel Tyczynski MD, PhD, Institute of Cardiology, 42 Alpejska St, 04-628 Warsaw, Poland, e-mail: medykpol@wp.pl Received: 30.08.2013, accepted: 9.01.2014. 


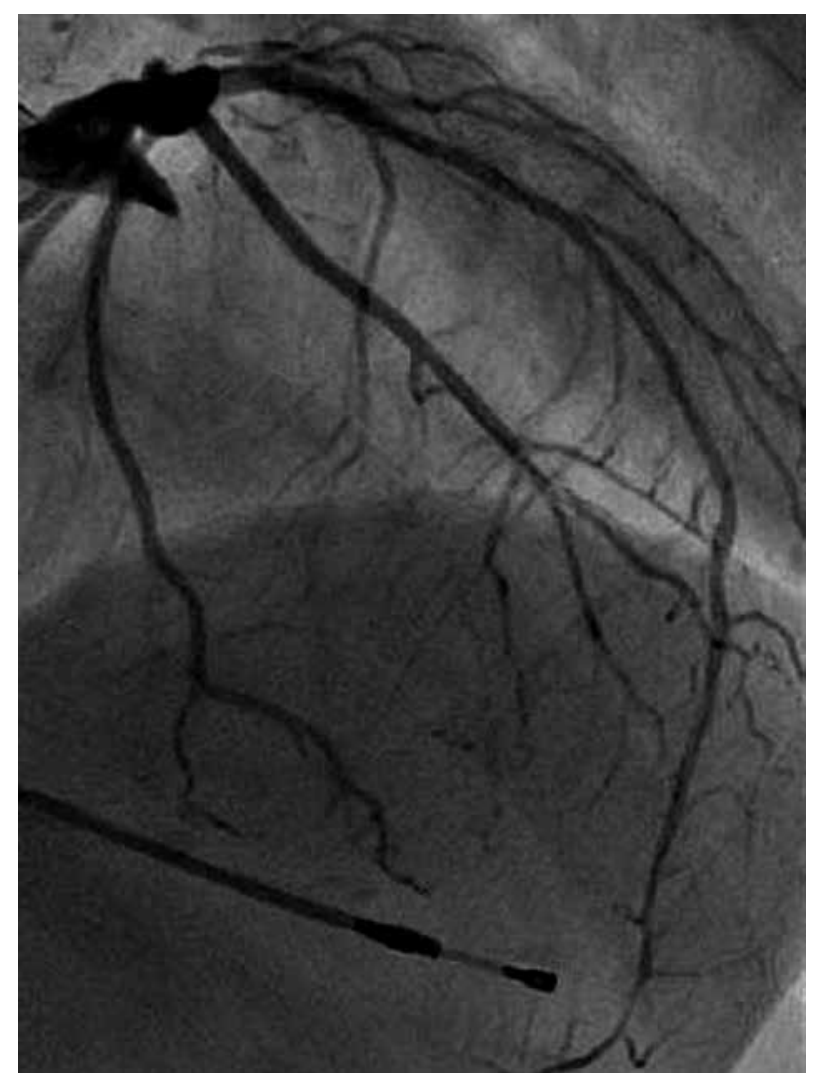

Figure 1. Control coronary angiography in 2011 showing only discrete narrowings

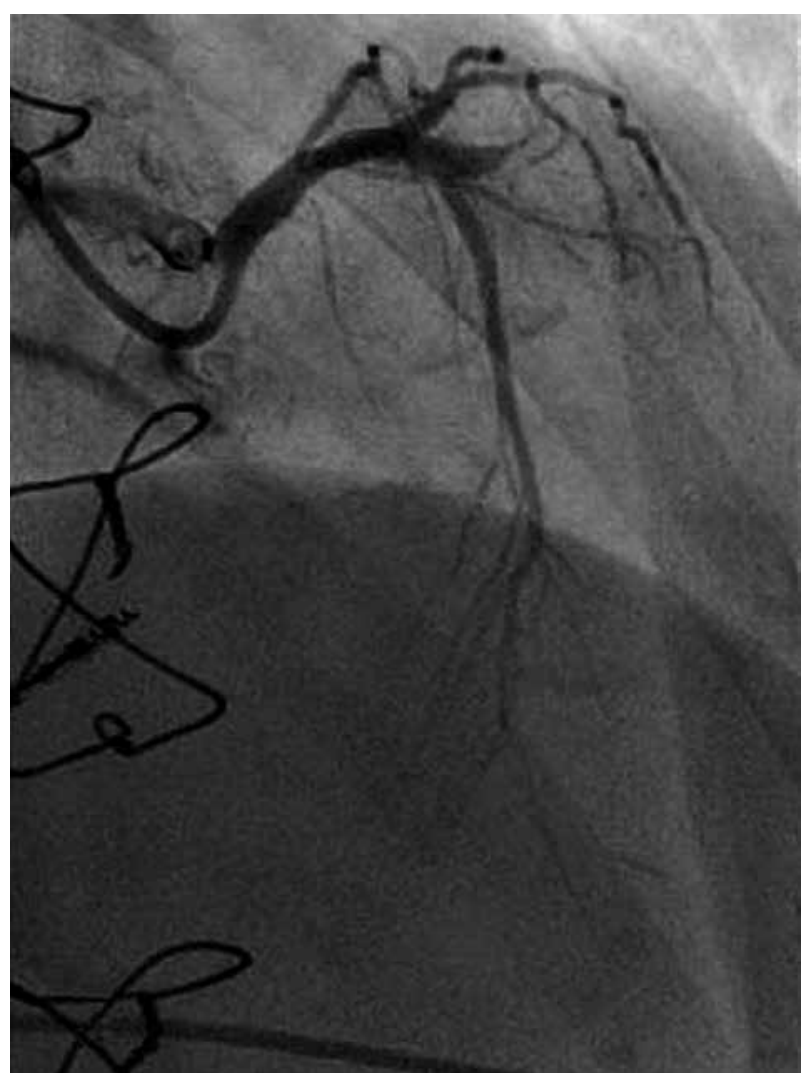

Figure 2. Occluded proximal segment of the left anterior descending coronary artery in 2013

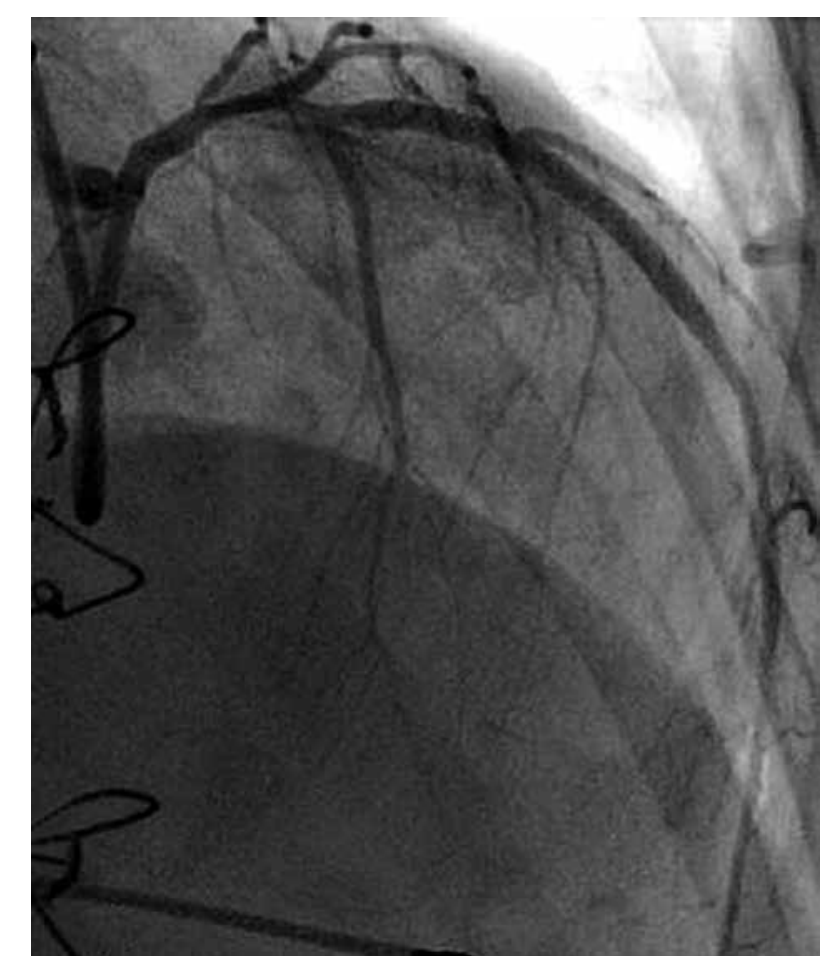

Figure 3. Left anterior descending coronary artery after stent implantation suistic [2-4]. In the first systematic review of ACS in HTx patients, unspecified ST changes were observed in 5 of 22 patients [5]. A possible explanation could be that cardiac allograft vasculopathy (CAV) differs from traditional coronary atherosclerosis. Intimal smooth muscle hyperplasia is diffuse and involves the entire circumference. Microscopically it is characterized by intense cellular proliferation - mainly of smooth muscle cells and inflammatory infiltrates (lymphocytes and monocytes). Often vascular changes also involve the distal part of the coronary tree. The prevalence of CAV remains as high as 30\% at 5 years, and $45 \%$ at 8 years after HTx, limiting survival [6]. Thus prevention of CAV is of utmost importance. Selected statins may have a beneficial effect on CAV [7]. Tacrolimus might have an advantage over cyclosporine A for endothelium function, but the superior freedom from $\mathrm{PCl}$ remains questioned [8].

Secondly, as a result of cardiac denervation, HTx patients with ACS present with rather atypical symptoms and typical symptoms during ACS are very rare [9]. The most frequently reported symptom was weakness followed by dyspnea [10].

Restenosis rates after elective $\mathrm{PCI}$ for CAV are higher as compared to $\mathrm{PCl}$ in native coronary arteries [11]. The observations from single-center retrospective studies 
indicate that drug-eluting stents are characterized by a lower rate of in-stent-restenosis than bare metal stents in CAV [12]; however, the results are contradictory [13] and the beneficial effect of the drug is questioned [14]. The follow-up observations after PCI for ACS in HTx patients are limited to only single reports [4].

\section{References}

1. Fazio G, Sutera L, Vernuccio D, et al. Symptomatic acute myocardial infarction in a patient bearer of heart transplantation following ischemic heart disease. Int J Cardiol 2008; 124: 233-236.

2. Di Cori A, Petronio AS, Gemignani C, et al. Symptomatic acute myocardial infarction in a cardiac transplant recipient successfully treated with primary coronary angioplasty: evidence of prognostic importance of chest pain after cardiac transplantation. J Heart Lung Transplant 2005; 24: 1146-1149.

3. Peter S, Hulme O, Deuse T, et al. ST-elevation myocardial infarction following heart transplantation as an unusual presentation of coronary allograft vasculopathy: a case report. Transplant Proc 2013; 45: 787-791.

4. Varotto L, La Vecchia L, Fontanelli A. Abciximab in ST-elevation acute myocardial infarction occurring in a heart transplant recipient and treated with stenting. J Invasive Cardiol 2006; 18: 134-136.

5. Bildirici U, Celikyurt U, Ural E, et al. Successful percutaneous intervention to acute myocardial infarction presenting with typical chest pain in transplanted heart. Circ J 2009; 73: 2166-2168.

6. Benden C, Aurora P, Edwards LB, et al. The Registry of the International Society for Heart and Lung Transplantation: Fourteenth Pediatric Lung and Heart-Lung Transplantation Report--2011. J Heart Lung Transplant 2011; 30: 1123-1132.

7. Kobashigawa JA. Statins and cardiac allograft vasculopathy after heart transplantation. Semin Vasc Med 2004; 4: 401-406.

8. Guethoff S, Meiser BM, Groetzner J, et al. Ten-year results of a randomized trial comparing tacrolimus versus cyclosporine $a$ in combination with mycophenolate mofetil after heart transplantation. Transplantation 2013; 95: 629-234.

9. Bildirici U, Celikyurt U, Ural E, et al. Successful percutaneous intervention to acute myocardial infarction presenting with typical chest pain in transplanted heart. Circ J 2009; 73: 2166-2168.

10. Gao SZ, Schroeder JS, Hunt SA, et al. Acute myocardial infarction in cardiac transplant recipients. Am J Cardiol 1989; 64: 1093-1097.

11. Bader FM, Kfoury AG, Gilbert EM, et al. Percutaneous coronary interventions with stents in cardiac transplant recipients. J Heart Lung Transplant 2006; 25: 298-301.

12. Lekston A, Zakliczyński M, Gasior M, et al. Comparison of longterm results of drug-eluting stent and bare metal stent implantation in heart transplant recipients with coronary artery disease. Kardiol Pol 2010; 68: 131-134.

13. Nfor T, Ansaarie I, Gupta A, et al. Comparing long-term outcomes between drug-eluting and bare-metal stents in the treatment of cardiac allograft vasculopathy. Catheter Cardiovasc Interv 2009; 74: 543-539.

14. Wellnhofer E, Hiemann NE, Hug J, et al. A decade of percutaneous coronary interventions in cardiac transplant recipients: a monocentric study in 160 patients. J Heart Lung Transplant 2008; 27: 17-25. 